\title{
Prensa literaria en Andalucía, Revistatlántica de poesía como paradigma de publicación multicultural (1991-1998)
}

\author{
Aurora Labio Bernal \\ Grupo de Investigación en Estructura, Historia y Contenidos de la Comunicación
}

Para difundir ese mensaje universal que es la poesía nace en 1991 RevistAtlántica de poesía. Sus fundadores, José Ramón Ripoll y Jesús Fernández Palacios, inician desde Cádiz esta publicación en la que dan cabida a escritores de todo el mundo, contribuyendo desde sus páginas a conjugar todas las tendencias y estilos en un modelo de publicación multicultural.

Autores españoles de distintas generaciones se dan la mano con poetas hispanoamericanos como Alvaro Mutis o Mariano Brull, por citar sólo dos referencias.

El abanico se amplía con nuestros vecinos europeos: el francés René Char, los italianos Sanguineti y Gluseppe Conte, o el inglés Christopher Middleton. La lengua inglesa entra también en las páginas de RevistAtlántica a través de autores norteamericanos, como Paul Bowles y Allen Ginsberg.

La publicación mantiene además su espíritu cosmopolita al incluir a poetas asiáticos y africanos, de los que reproduce, facsimilarmente, parte de su obra. Es el caso del sirio Muhamad Al-Magut, el turco Nazum Hikmet o el marroqui Abdellatif Laabi.

Las referencias aquí hechas son solo una pequeña parte de la riqueza literaria y multicultural que incluye RevistAtlántica de poesía. Quizá artículo no sea suficiente para comprender el contenido y el alcance que posee la publicación, aunque si proporciona un acercamiento figuroso de la misma para todos aquellos entendidos o, simplemente, amantes de la poesía hecha en diferentes lenguas. A partir de aquí, sólo queda adentrarse en la página de la revista, sumergirse de lleno en toda esa poesía escrita en distintos idiomas y que busca conseguir un pensamiento contemporáneo y universal.

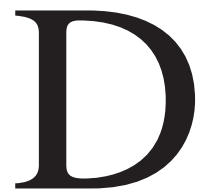

esde un idioma unitario, la RevistAtlántica de Poesía quiere re flejar en sus páginas cuantos textos compuestos en cualquier lengua traten de elevar el espíritu humano. Ante todo, la música y el signo para descifrar la eterna melodía de nuestra existencia, y en ella no hay dibujo más hermoso que el murmullo y los símbolos de cada idioma. Deseamos convertir esta revista en un punto de encuentro perma- 
nente entre las voces más señeras de nuestra múltiple realidad contemporánea". 1

\section{Introducción}

Con estas palabras del poeta y periodista gaditano José Ramón Ripoll, ve la luz en Cádiz RevistAtlántica de Poesía en la primavera de 1991. La publicación supone desde entonces, y es en la actualidad, un proyecto literario que supera la esfera local y nacional, y abre sus páginas a los poetas de todo el mundo.

La limitación de espacio en las siguientes líneas impide un análisis profundo de los quince números de RevistAtlántica que, hasta el momento, han sido publicados. Es, sin embargo, ocasión de realizar un estudio riguroso para conocer la diversidad de autores y obras que contienen estos volúmenes. Antes de ello, parece conveniente realizar un recorrido histórico por las revistas literarias que han existido en Cádiz, lo que nos permitirá descubrir el lugar que ocupa RevistAtlántica dentro de este tipo de publicaciones.

\section{2.- Revistas literarias en el Cádiz del siglo $\mathrm{XX}$}

En una provincia como Cádiz, su reciente tradición poética se ve compensada con un gran número de revistas literarias que se convierten rápidamente en órganos de expresión donde se inician la mayor parte de los autores. Ya a principios de este siglo, el modernista Eduardo de Ory publica Azul y, más tarde, España y América, que coincide con RevistAtlántica en su vocación cosmopolita, aunque más restringida hacia Hispanoamérica.

Muchos de los miembros de la Generación del 27 se iniciaron en otra publicación gaditana, la revista Isla, fundada por Pedro Pérez Clotet. Isla conocerá una primera etapa antes de la Guerra Civil Española, y una segunda, a partir de 1949, en la que va perdiendo calidad para convertirse en órgano de expresión de escritores afectos al Régimen franquista.

En los años cincuenta, surge Platero, revista del grupo de poetas gaditanos del mismo nombre, entre los que se encontraban Fernando Quiñones, Pilar Paz, Felipe Sordo, José Caballero y Julio Mariscal.

Con un único número pasa a la historia de las revistas literarias, Marejada, que nace y muere en la primavera de 1973. La publicación se

\footnotetext{
José Ramón Ripoll, director de RevistAtlántica de Poesía, Números 1-2 RevistAtlántica, Cádiz 1991
} 
inaugura con unos inéditos de Borges y se convierte, pese a su corta vida, en una referencia importante en el mundo literario. En Marejada encontramos, además, el embrión de lo que en los años noventa será RevistAtlántica de Poesía.

Desde entonces, y para encontrar una revista de similar importancia a las citadas, hay que esperar hasta 1982, cuando Francisco Bejarano y Felipe Benítez ponen en marcha Fin de Siglo, en Jerez de la Frontera. El profesor y periodista Ramón Reig comenta en su libro Panorama poético andaluz:

"Fin de Siglo se configuró como una publicación notable con proyección nacional, lo cual no es poco cuando estamos acostumbrados a que todo nos venga desde la capital de la Corte y, de hecho, aún no habíamos conseguido los andaluces una publicación literaria de auténtica altura, capaz de hacer llegar al resto del Estado y al extranjero la voz y la opinión de algo tan decisivo como el hacer y el pensamiento poético del sur de España". 2

Desde 1986, año en el que se publica el último número de Fin de Siglo, se suceden en la provincia otras revistas literarias de menor trascendencia hasta que en 1991 nace RevistAtlántica de Poesía. Nos encontramos entonces con una publicación más cosmopolita que las anteriores, que ha trascendido la esfera nacional y que goza de un gran reconocimiento en todo el mundo, sobre todo en tierras hispanoamericanas.

Dirigida por José Ramón Ripoll y Jesús Fernández Palacios, RevistAtlántica de Poesía cuenta con un Consejo Asesor en el que figuran Rafael Alberti, Carlos Edmundo de Ory, Pilar Paz, José Caballero Bonald, Fernando Quiñones y Francisco Bejarano.

La revista, que nació bajo el mecenazgo del Ayuntamiento gaditano, pasa a manos del Servicio de Publicaciones de la Diputación Provincial de Cádiz a partir de su tercer volumen. Además, desde el número nueve, la publicación está patrocinada por el grupo Telefónica.

\section{3.- RevistAtlántica de Poesía. Autores españoles}

Presentada en Madrid, Barcelona, Salamanca, París, Bremen, Nueva York, Miami, Bogotá y San Juan de Puerto Rico, entre otros lugares,

\footnotetext{
2 REIG, Ramón: Panorama poético andaluz (en el umbral de los años noventa), Editorial Guadalema, Colección Ensayo, Sevilla, 1991, p. 36.
} 
RevistAtlántica ha llamado la atención de numerosos entendidos y ha recibido críticas muy favorables en diversas ocasiones.

Estructurada en dos partes, la revista ha sido además lugar de encuentro de poetas de todo el mundo. Desde el primer volumen y hasta el último número publicado cuando redacto estas líneas, RevistAtlántica recoge en sus páginas un largo número de escritores españoles, europeos, americanos, e incluso africanos y asiáticos. Resulta por ello muy difícil destacar a unos autores en detrimento de otros, ya que al representar muy diversas tendencias y pertenecer a distintos países, poseen un interés intrínseco que motivaría la necesidad de hacer mención a todos ellos. La limitación de espacio, en esta ocasión, nos obligaría a realizar una relación casi inventarial de todos los poetas y obras, algo que no sería de mucha utilidad.

Por este motivo, creo más acertado llevar a cabo una selección de las figuras y obras que resulten más representativas y de aquellas otras que supongan alguna novedad al panorama poético contemporáneo, no sin antes hacer una invitación al lector para que se sumerja en las páginas de todos y cada uno de los números de RevistAtlántica, tarea que sin duda alguna resulta de gran utilidad y placer para cualquier amante de la poesía.

Comenzando con los autores españoles, merece especial atención las traducciones que de otras lenguas nacionales hace RevistAtlántica. Nos encontramos así, en el primer volumen, con la traducción que el profesor Antonio Jiménez hace del catalán Joan Margarit para deleite de los lectores: "Me importa lo que sucede en la noche estrellada de un verso" (en "Mujer de primavera", del libro Edat Roja). El leridano Jaume Pont aparece en el número cuatro con su Raó d'atzar, mientras que la traducción que José Ramón Ripoll hace de Quima Jaume en el número siete constituye un valioso hallazgo. Se trata del inédito Del temps i dels somnis, donde la poetisa nos obsequia con delicados y rítmicos versos llenos de intensidad: "Hoy hago las maletas/ y no he guardado en ellas tus recuerdos./ Los dejo encima de la cómoda,/ cerca de los papeles/que no quiero mirar,/ porque el ojo del ayer/ me acecha:/ son fantasma que amo/ con pesadumbre y miedo. ("Fantasmas", en Del tiempo y de los sueños).

La poesía gallega también tiene su hueco en RevistAtlántica, donde encontramos a Xavier Rodríguez Baixeiros en el número cuatro, con otro poemario inédito, Visitantes, y a Ramiro Fonte, considerado por la crítica como uno de los autores más representativos de la literatura gallega actual. 
Con un estilo romántico, Fonte ofrece en el volumen seis de la revista sus Cinco Poemas e Cantares, de los que he seleccionado el siguiente fragmento: "En la calle del desencanto/ Quiere aguardarme una esquina/ Para guardar con el hastío/ Y con el dolor una cita/ " ("En la calle del desencanto").

El resto de los poetas españoles que aparecen en RevistAtlántica lo hacen ya con obras en castellano. La profusión de nombres permite distinguir entre las figuras consagradas y los nuevos valores literarios. En el primer caso, aparece José Hierro, con unos poemas inéditos que contribuyen a realzar el valor del volumen uno/dos de la revista: "Entro en la seda del poema roto/ donde alguien, que fui yo, murió más de una vez./ No hay nadie, nada: tan sólo un automóvil./ Pongo el motor en marcha: le hablo de libélulas,/ de gusanos de seda" ("Prólogo con libélulas y gusanos de seda", en el libro Agenda).

De los más jóvenes poetas españoles, destaca el canario Rafael José Díaz, con su mundo de hermosas imágenes en Umbral de fuego.

Entre Hierro y Díaz, un largo índice de autores españoles. Algunos tan conocidos como Luis Antonio de Villena, con sus particulares historias poéticas: "Salía mucho en la tele, en los sesenta./ Papeles cortos, sí... Muy moderna, andaba en/ todas partes, con tíos, con canutos, pirada, divertida..." (De "Una chica de vida alegre", en Cayendo en el tiempo) o sus reflexiones sobre el amor: "La amistad dura más que el amor/ pero como él, al fin, es un sueño imposible."(De "De la amistad, en diciembre", en Cayendo en el tiempo, número seis, RevistAtlántica de poesía).

La aparición de otros poetas españoles sirve también para rendirles homenajes. Ocurre en el número uno con María Zambrano, a la que ya nos hemos referido, y con Aurora de Albornoz, vinculada a RevistAtlántica de forma muy especial, ya que fue una de las alentadoras de la publicación.

Como revista que nace en Cádiz, la publicación no puede olvidar a los poetas de su tierra y presenta así la obra de la jerezana Josefa Parra, poetisa joven en cuyos versos se nota la influencia profunda de la generación del 27, recordando incluso de manera directa a Salinas en su "Poema de la espera": "Y quizás hoy tampoco/ me permitas llegar por tu voz a tu boca,/ como suelo escalarte sin que tú lo percibas" (número 13).

Otros poetas de la provincia, que aparecen en el número 14, son Pilar Paz Pasamar y el chiclanero Fernando Quiñones, con unos bellos poemas en los que la tradición arábigo andaluza se deja sentir incluso en la transcripción exacta de algunas palabras. 


\section{4.- Autores hispanoamericanos}

Cuando en noviembre de 1991, Alvaro Mutis visitó Cádiz para apoyar con su presencia la continuidad de RevistAtlántica de Poesía, manifestó:

"El nombre mismo, RevistAtlántica, es un concepto muy importante que se tenga en cuenta en España: la España atlántica, la de Galicia, de Cádiz y Huelva, que estuvo frente a lo desconocido, que finalmente puede ser también la poesía, que se convierte en lo revelado. A mí me parece que esta revista encarna perfectamente un sueño, un ideal, que tenemos en Iberoamérica, en Hispanoamerica, en America Latina y en España", .

Estas palabras del escritor colombiano describen una realidad que se hace patente en la revista. RevistAtlántica, a pesar de ser foro común de voces poéticas mundiales, posee una estrecha relación con los escritores hispanoamericanos.

Desde las primeras páginas encontramos al cubano Gastón Baquero, al argentino Roberto Juarroz y a los peruanos Germán Belli y Javier Sologuren. Chile también está presente en la revista a través de dos nombres claves, Oscar Hahn y Gonzalo Rojas. ( ${ }^{\circ} 3$ y n⿳0 4). Los versos de Hahn ofrecen visiones llenas de contrastes: "Eran las doce del día y de golpe empezó a anochecer/ (...) Las esferas estaban suspendidas sobre el agua inmóvil/ claramente visibles en la oscuridad" (De "A las doce del día" en Versos robados). El flujo de estos autores hispanoamericanos es continuo en RevistAtlántica, y se ve reforzado, además, por los "Documentos" especiales que hacen referencia a sus vidas y obras.

Es el caso del cubano Mariano Brull, representante de la llamada "poesía pura", a quien se le dedica parte del número tres con una selección de sus poemas y un artículo introductorio de Manuel Díaz Martínez.

En otros casos, como en el de ${ }^{4}$ Alejandra Pizarnik, RevistAtlántica publica una correspondencia inédita entre la poetisa argentina y ${ }^{5}$ Osias Stutman durante 1970. Se ofrece así al lector claves personales de la escritora que contribuyen a un mejor conocimiento de su obra. $\left(\mathrm{n}^{\circ} 4\right)$.

\footnotetext{
Diario de Cádiz, jueves, 7 de noviembre de 1991.

4 Alejandra Pizarnik nació en Buenos Aires en 1936. Poetisa y ensayista, publicó La tierra más ajena, Los trabajos y las noches y Los pequeños cantos, entre otros libros. Después de su suicidio, en 1972, se han publicado póstumamente otras obras suyas, entre las que destacan Textos de sombra y últimos poemas.

5 Osias Stutman es poeta, traductor y prestigioso científico argentino, catedrático en la Universidad de Corneille (Nueva York).
} 
Uno de los documentos que ocupa mayor extensión en RevistAtlántica es el dedicado a Jorge Eduardo Eielson ${ }^{6}$, en el noveno volumen. Se incluye, en esta ocasión, una entrevista con el artista peruano, así como una selección de sus poemas. Además se ameniza todo ello con opiniones que sobre Eielson tienen gente como Roberto Paoli, Alvaro Mutis, Rubén Vargas o Yolanda Pantin. La riqueza de este "Documentos" aumenta con las ilustraciones realizadas por el propio artista, que permiten una mejor comprensión del sentido que sobre Arte, en su conjunto, tiene Eielson.

Un monográfico de estas características había aparecido ya en el número siete, dedicado a Eugenio Florit ${ }^{7}$, poeta español cuya trayectoria literaria se desarrolló en Cuba. Sobre este especial, que coincide con el noventa cumpleaños del poeta, José Ramón Ripoll ${ }^{8}$ afirmaba en octubre de 1993:

"Florit es un hombre español, cubano y norteamericano, con una poesía cargada de un 'atlantismo' que queríamos rescatar para la revista”.

Este "Documentos" aparecerá con una gran profusión de fotografías y riqueza de contenidos, ya que junto una selección de poemas, aparece también una entrevista que Florit concedió a Jesús Fernández Palacios, así como los comentarios que sobre la vida y la obra del, considerado por muchos, representante de la poesía cubana realizan Gastón Baquero, José Olivio Jiménez y José Hierro. La última parte del monográfico la ocupan doce cartas que envían a Florit distintos personajes del mundo literario, como Jorge Guillén y Vicente Aleixandre, y en las que comentan la obra del poeta, del amigo. El especial se convierte así en una fuente de gran valor para cualquier estudioso de Eugenio Florit.

Un documento que podíamos haber incluido en el epígrafe anterior es el dedicado a Federico García Lorca, en el número 12 de la revista, sin embargo la investigación que se presenta está centrada en la figura de Lorca dentro de la literatura uruguaya, por lo que parece más apropiado incluirlo en este bloque. A partir de este estudio, firmado por Pablo Rocca, conocemos la influencia que el poeta granadino tuvo en este país, desde que lo

\footnotetext{
6 Jorge Eduardo Eielson es poeta, artista plástico y filósofo peruano, y está considerado como uno de los representantes del llamado "Nuevo Humanismo". Actualmente reside en Milán.

7 Eugenio Florit nació en Madrid en 1903, y emigró a Cuba en 1917, donde realizó la mayor parte de su obra literaria. Entre sus libros se encuentran Treinta y dos poemas breves, Conversaciones a mi padre y Hasta Luego.

8 Diario de Cádiz, domingo, 24 de octubre de 1993
} 
visitó entre el 30 de enero y el 18 de febrero de 1934. La obra de Lorca comienza entonces a ser conocida por escritores uruguayos, difundida de forma más profunda en el país por Margarita Xirgu (que se exilia en Uruguay a partir de 1947) y José Bergamín, que llega casi al mismo tiempo a Montevideo.

Este documento, se detiene al final en la obra de autores uruguayos influidos por Lorca como son Juvenal Ortiz Saralegui, Juan Cunha, Pedro Picatto y Washintong Benavides, del que se publican también su poemas en este mismo número.

Otro documento de interés es el dedicado en el número 13 al colombiano José Asunción Silva, en el centenario del poeta. En el estudio se mezcla la biografía personal y poética del autor, con el llamativo análisis de las citas que dejó poco antes de su suicidio en 1896.

RevistAtlántica realiza otra estrategia de acercamiento a escritores hispanoamericanos a través de sus inéditos como ocurre en la tercera entrega, con Las soledades de Babel, de Mario Benedetti o en el número cuatro con el peruano Antonio Cisneros y Las inmensas preguntas celestes.

Podemos citar dos casos en los que la tradición cultural hispanoamericana se deja sentir de forma palpable en sus obras inéditas, ya sea en su lenguaje o en su contenido. Nos referimos al colombiano William Ospina y al boliviano Pedro Shimose, que aparecen en el número once.

Ospina recupera el sentimiento indígena en su poema "9 de Abril de 1948": "Para entender el modo como decía "patria'/ debes haber oído al viejo U'wa/ narrando el vuelo de las tijeretas,/ sentir un soplo de águilas arcaicas/ sobrevolando un territorio eterno,/ y saber, como saben el kogi y el sikwani,/ que somos estos mares, estas selvas,/ que las gentes del agua no son viajeros codiciosos/ sino el oro viviente de regiones muy hondas”. (Del Libro ¿Con quien habla Virginia caminando hacia el agua?).

Mientras, Shimose nos transporta con sus palabras y su ritmo poético al continente que le vio nacer: “(...) tampoco oiré los ecos/ de un bongó batido por un negro de los Yungas,/ ni me embriagarán los embelecos/ ni las sandungas/ de una muchacha loca por el cine y la poesía" (Del libro Riberalta).

Junto a todos estos poemas en español, la revista recoge también la obra de cinco autores en lengua indígena. En el número diez aparecen así las obras de cinco poetas mejicanos redactadas en Tzotzil, Maya-Chantal, Maya-Peninsular y Mazateco, una muestra que supera lo anecdótico para adentrarnos 
en otra forma de hacer poesía, y que contribuye a reforzar el talante abierto de la publicación gaditana.

Hay que hacer notar, por último, que RevistAtlántica no olvida tampoco a los poetas brasileños, con los que, a pesar de la diferencia idiomática, nos une la misma tradición cultural. Como representantes de la poesía de aquel país, la publicación nos ofrece a los brasileños José Paulo Paes y Sebastiao Uchoa Leite, con un total de once poemas traducidos del portugués.

\section{Autores europeos y norteamericanos}

La vocación cosmopolita con la que nace RevistAtlántica hizo que desde el principio prestara también atención a la poesía escrita en otras lenguas distintas a la española. Es lógico, pues, que nuestros vecinos europeos aparezcan en sus páginas junto con los otros grandes autores occidentales, los norteamericanos.

Con ocasión de la presentación de la revista en París, la publicación editó una separata especial traducida al francés, e incluyó en sus "Documentos" a doce poetas galos contemporáneos, con obras, en algunos casos, inéditas. Se trata de una lista de autores en la que se encuentran los consagrados Guillevic, Jean Claude Renard, Yves Bonnefoy y Henri Meschonnic, y otros menos conocidos para el público como Dominique Sampiero y Chantal Bizzini.

El perturbador René Char está presente en el primer volumen: "Nacen los hombres, trabajan, se pierden, con el corazón unido o desunido en mil motivos. Un genio sombrío atormenta a algunos. Que sea instantáneamente separado de su aliento y sus cenizas,/todo aquel que, triturando inocencia y dolor, cierre esta vía" (De "Callejuelas en el año 1978", en Todos se han ido). Además, parte del "Documentos" del número diez está dedicado al mismo poeta bajo el título "René Char en cuarenta instantáneas".

Otras veces los franceses se adentran en las páginas de la revista mediante ensayos, como ocurre con Gaston Bachelard en su reflexión sobre la creación literaria titulada "Las metáforas de la dureza", inédita en español (número 8 de RevistAtlántica).

La poesía portuguesa aparece también representada en casi todas las entregas por nombres como Amadeu Baptista ( $\left.n^{\circ} 8\right)$, Eugenio de Andrade (n5) o Antonio Ramos Rosas ( $n^{\circ}$ ). Un ejemplo muy singular entre estos poetas es el de Al Berto, que en el número siete de la revista plasma en sus versos parte del universo pictórico que conocemos. Son poemas personales, visio- 
nes del poeta ante la obra de Zurbarán, monólogos interiores inspirados en Van Gogh, en Kandinsky: "Mucho antes de haber adoptado formas/ rigurosamente geométricas (para huir de la anarquía)/ pinté este arco negro uniendo dos zonas/ del mismo paisaje: puente oscura/ por donde-tú que me miraspuedes pasar/ al encuentro de la intensa llama de las mañanas" (De "Kandinsky escondido tras la tela", en el libro La secreta vida de las imágenes). La traducción del portugués es de José Luis Puerto.

El Mediterráneo llega también hasta RevistAtlántica a través de la poesía italiana. Uno de los primeros autores de este país que figuran es Edoardo Sanguineti, que acudió a Cádiz para presentar el número tres de la revista. Se abren así las puertas a la Vanguardia con poemas de Sanguineti nunca antes traducidos al español, y con algún inédito, que inauguran RevistAtlántica y su voluntad de transigir con todas las tendencias poéticas.

De Sanguineti se recogen también unas cartas de Cesare Pavese, Giuseppe Ungareti y Pier Paolo Pasolini. Se trata de las respuestas que estos autores le envían al escritor genovés tras haber recibido unos poemas suyos en la década de los cincuenta. Son unos documentos que hasta ahora habían permanecido inéditos, y que poseen un valor añadido al reproducir los originales de las misivas ( $\left.n^{\circ} 5\right)$.

Giuseppe Conte, con El océano y el muchacho, y Attilio Bertolucci, con una selección de poemas de sus libros Viaggio d'inverno y La camera da letto, son otros de los autores italianos que aparecen en la publicación. $\left(n^{\circ} 6\right.$ y $\left.n^{\circ} 7\right)$.

Poetas ingleses y norteamericanos conforman el último gran bloque de autores en RevistAtlántica. Como veremos más adelante, también se recogen obras de escritores alemanes, suizos y belgas. Además, se reserva un espacio considerable para poetas árabes, con lo que se recuperan así unas raíces culturales que amplían las coordenadas poéticas del lector.

Nos detenemos antes en los autores de habla inglesa. Philip Larkin aparece en el tercer tomo de la revista con unos poemas de fácil y bella lectura, traducidos por J.M. Benítez Ariza.

Larkin contrasta, sin duda alguna, con su compatriota Christopher Middleton, autor de una poesía inclasificable, tanto por el lenguaje como por el contenido: "Los miembros todos/ Mas no un punto/ Estirándose, entonces, en sus pliegues,/ Tanto, cuanto más, desnudos (De "21 Micropoemas misceláneos", en su libro Cuasiceros).(n5)

De Estados Unidos llega a RevistAtlántica el evocador Paul Bowles, 
seguido en el octavo número de la poesía rotunda de Allen Ginsberg, traducida por Carlos Edmundo de Ory: "Levantaos, prisioneros de vuestra mentalidad/ Levantaos Neuróticos de la Tierra/ Para la Liberación de los tumultos interiores/ Un Mundo Sagrado está naciendo" (De "la Quinta Internacional").

Además de los juegos compositivos y lingüísticos de Robert Duncan $\left(\mathrm{n}^{\circ} 8\right)$, la revista trae la poesía con tintes sociales de Williams Carlos Williams, del que Octavio Paz comentó que era el autor de los poemas "más vivos de la poesía moderna norteamericana".

La sección "Documentos" también recoge la obra de autores norteamericanos. Parte del número seis está dedicado a la escritora neoyorquina Djuna Barnes, de la que se recoge una selección de poemas traducidos y prologados por Osias Stutman. Otros poetas norteamericanos en los que RevistAtlántica también se detiene son Theodore Roethke y William Stanley Merwin ( ${ }^{\circ} 1$ $\left.2 \mathrm{y} \mathrm{n}^{\mathrm{o}} 11\right)$.

Junto a todos estos autores, aparecen más discontinuamente poetas alemanes, e incluso belgas, suizos, checos y rumanos. Imposible es hacer referencia justa a todos ellos en tan corto espacio, pero parece de interés detenerse en el Documento que aparece en el número 14 de la revista dedicado al belga Henry Michaux. Como ocurría con Eielson, se ofrece un estudio sobre el sentido que el arte tiene para el autor en su conjunto y se ilustra con dibujos que Michaux hizo bajo la influencia de la mezcalina, como una forma de indagar en su interior. Por último, y como en otras ocasiones, se incluye un texto del artista que nos permite así conocer su obra escrita también.

Por último, y de la mejor manera, cerramos este bloque con el "Epílogo" del alemán Michael Augustin, un ejercicio de ingenio que reproducimos: "No me enterréis/cuando me muera./ Tomadme/ como señal de lectura./ Aplastadito/ entre las hojas,/ quiero ser/ de utilidad,/ allí donde la historia/ continúa". (En su libro Vamos a por tabaco).

\section{Un hueco para los poetas asiáticos y africanos}

La afinidad con la cultura árabe, debida a nuestra vinculación en el pasado, es algo que también preocupa a RevistAtlántica de Poesía. Buscando su mayor alcance dentro de la comunicación poética, la publicación reproduce fácsimilarmente parte de la obra de autores en lengua semita, traducida al castellano. 
En el número cinco aparecen dos poetas que escribieron muchos de sus versos desde prisiones en las que fueron encarcelados por motivos políticos. Son el sirio Muhamad Al-Magut y el turco Nazim Hikmet. La poesía de ambos está dominada por un dramatismo valiente que impactan al lector por la dureza de sus bellos contenidos:

"Muchas veces intenté/ limpiar este bolígrafo de la tinta/ como se limpia el puñal de la sangre/ y marchar de esta ciudad,/ aunque montado en la silla de una pared,/ pero he fracasado". (De "Mensaje a la Alquería", en el libro La alegría no es profesión mía, de Muhamad Al-Magut).

Siguiendo esta línea está el argelino Jean Sénac, poeta que escribe en francés, pero cuya obra ha de leerse teniendo en cuenta el contexto político de su país durante la lucha por su independencia a mediados de este siglo. Es una poesía llena de apuntes político-sociales, que se convierte en su personal forma de denuncia: "Con la rabia, la mugre y la vulgaridad,/ ¿Ministros, qué fundaréis?/ ¿Qué canto con este alboroto?/ ¿Qué ciudad con estos añicos?" (En Esta ciudad, en el número diez de RevistAtlántica).

El tunecino Hassin Al-Kahouaji se preocupa más por la belleza de la forma, y realiza experimentos compositivos que lo alejan de su tradición a partir de juegos póeticos: "Pregunta al poeta si conoce un borracho/ que trasnoche más que la luna". (En el libro Más raro que los relámpagos de verano, más suave que las nubes de otoño, $\mathrm{n}^{\circ}$ 6).

Los únicos casos de poesía no contemporánea se publican en el número siete de RevistAtlántica, y pertenecen a Muhyi-D-Din Ibn Al-'Arabi, autor nacido en Murcia, que vive en la transición del siglo XII al XIII, y Yalal Addin Rumi, que vive ya en el propio siglo XIII. Ambos autores se caracterizan por la escritura de unos versos llenos de armonía, luminosidad y colorido y que están cargados de un gran misticismo en Yalal Addin Rumi: "Por amistad, amigo, de tí cerca estamos./ Allá donde pisas, por tí, suelo somos./ Y como merece la fe del amor/ en tí el mundo vemos y a ti no te vemos." (En el libro Rubayatas del Diván de Shams Tabrizî).

Junto a estos poetas asiáticos, ReivstAtlántica, va incluyendo cada vez más a autores africanos, poco conocidos actualmente dentro del panorama poético.

Es el caso del marroquí Abdellatif LaâBi, con unos versos que recuerdan a los proverbios y cantares machadianos: “¿Me aman las palabras que yo amo? ¿Si las desgrano que me quedará por decir?” (de Spleen de Casablanca, número doce). 
Del número catorce destacamos la obra del senegalés Charles Carrère, no sólo por su cuidada composición, sino también por su significado: “(...) el mundo gime/ de comer/ demasiado/ de no comer bastante/ de no comer nada/ la misma hambre/ sobre las misma miseria/ sobre la misma muerte (...)" (de Memorias de la lluvia, número 14).

Con la inclusión de estos autores asiáticos y africanos, RevistAtlántica completa el quehacer literario de gran parte del mundo. Son quince números los publicados hasta el momento, más de tres mil páginas por las que han desfilado cerca de trescientos poetas de todo el mundo. Con el número quince la revista ha cumplido, además, siete años de existencia, lo que borra el carácter efímero, atribuible a la mayoría de las publicaciones literarias. Los responsables de RevistAtlántica han asegurado ya el lanzamiento del número dieciséis, que probablemente estará en imprenta cuando se publique este artículo. Como adelanto a este número, podemos incluir la presencia del belga Paul Van Ostajen, del argentino Pablo Narral, del francés Lionel Ray, traducido por François Michel Durazzo, y del ruso Osip Mandelston, prologado y traducido por Lola Díaz, nieta de José Díaz.. Hay que destacar igualmente que, coincidiendo con el centenario del nacimiento de Federico García Lorca, la sección Documentos está dedicada al poeta y comienza con un excelente ensayo de Dionisio Cañas titulado "Carta a Federico". Centrado el Documento en la estancia de Lorca en Nueva York, se realiza también la selección de doce poetas hispanos en la ciudad de los rascacielos, entre los que podemos destacar al chileno Raúl Barrientos, el dominicano Alexis Gómez Roza, los puertorriqueños José Manuel Torres Santiago, David Cortés Cabán e Iván Silén, los argentinos Mercedes Roffé y Osias Stutman, el peruano Isaac Goldemberg o el español Hilario Barrero. Por último, la sección se completa con interesantes fotografías del poeta granadino en Nueva York y de su amante norteamericano, Philippe Cumming. Además, el número en su conjunto está ilustrado con grabados y dibujos de la misma ciudad.

La publicación, de esta manera, garantiza su espíritu cada vez más cosmopolita a través de sus páginas abiertas, de sus ventanas oceánicas, a la espera de que entre cualquier vestigio de ese idioma universal que llamamos poesía. 